\title{
EVALUATION OF CLINICAL OUTCOME OF FOUR LEVELS ANTERIOR CERVICAL DISCECTOMY
}

\author{
By
}

\author{
Ahmed El-Sayed Ahmed, Maamoun Abou Shohsa, Islam Al-Aghory, \\ Wael Abd El-Fatah Hammad, Mohamed Barania, and Hussein Montaser \\ Roshdy* \\ Departments of Neurosurgery and Radiodiagnosis*, Faculty of Medicine, Al-Azhar \\ University
}

Corresponding author: Ahmed Elsayed Ahmed, E-mail: ahmedelsayed30@gmail.com

\begin{abstract}
Background: The modern paradigm for managing cervical disc diseases uses both ventral and dorsal approaches, with ventral procedures being more common. The ventral procedures consist primarily of discectomy, followed by fusion. The symptoms and syndromes of cervical disc diseases can be mimicked by a number of other neurological disorders.

Objective: To evaluate the efficacy of polyetheretherketone (PEEK) cage only in four levels anterior cervical discectomy as one of surgical option other than anterior cervical corpectomy, fixation by plat or posterior approach for cervical laminectomy, and assessment of post spinal surgery pain.

Patients and Methods: This was a prospective study including twenty adult patients with symptomatic four levels cervical disc disease operated upon by anterior cervical discectomy with inter-body cage fusion in the Neurosurgery Department at Al-Hussein University Hospital and Sednawy Health Insurance Hospital. The study was performed through the period from January 2018 to June 2020, and the follow up period was 24 months.
\end{abstract}

Results: At the time of diagnosis, the most common symptoms presented were neck pain, brachialgia, heaviness of the lower limbs, and urinary incontinence. All patients were managed by anterior cervical discectomy and fusion by stand-alone PEEK cages for four levels. The mean preoperative visual analogue score (VAS) was $6.05 \pm 1.14$ and reached $2.15 \pm 0.58$ by the $24^{\text {th }}$ month postoperative.

Conclusion: The procedure of multi-level anterior cervical discectomy with PEEK inter body cage fusion without plate fixation at four levels appeared safe and efficient, with improvement in long-term outcomes for pain and myelopathy, short inpatient hospital stay, and potentially short procedure duration.

Keywords: Cervical myelopathy; cervical radiculopathy; Four Levels Anterior Cervical Discectomy; PEEK cage.

\section{INTRODUCTION}

Cervical spondylosis is the disease associated with progressive degenerative changes of the intervertebral discs, joints, ligaments, and adjacent vertebrae. Multiple level cervical disc disease, especially three- and four-levels, may form a significant challenge to the spine surgeon (Shousha et al., 2012).

The modern paradigm for managing cervical disc diseases uses both ventral and dorsal approaches, with ventral procedures being more common. The ventral procedures consist primarily of discectomy, followed by fusion, but it 
carries the risk of accelerated juxta fusion degeneration (Cramer, 2013).

The symptoms and syndromes of cervical disc diseases can be mimicked by a number of other neurological disorders, including pain, myelopathy, or both and sometimes syndromes like amyotrophic lateral sclerosis, multiple sclerosis, and syringomyelia (Elias et al., 2017).

Diagnostic evaluations must keep this differential in mind patient history, detailed neurological examination, and radiographic imaging are the primary basis of diagnosis in cervical disc diseases, cervical magnetic resonance imaging scanning is currently the imaging modality of choice, although computed tomography scanning with or without myelography remains useful for better delineation of bony anatomy (Cho et al., 2014). Also, plain films with dynamic views are valuable adjuncts in the evaluation of spinal instability (Izzo et al., 2013).

Management choices include conservative or surgical management. In patients with mild stationary disease or who are poor surgical candidates, a trial of conservative management with rigid collar immobilization, symptomatic treatment, and physical therapy (SaterenZoller et al., 2015).

In patients with moderate-to-severe myelopathy, radiculopathy, or with progressive myelopathy, surgical management is indicated (Shousha et al., 2012).

Among the available options for treatment of the multiple levels cervical disc disease including anterior, posterior and sometimes combined approaches; anterior cervical discectomy with fusion (ACDF) remains the gold standard in treatment of single and two levels cervical disc disease. While data available for multiple levels (three and four levels) anterior cervical discectomy is still lacking (De La Garza-Ramos et al., 2016).

Multilevel cervical discectomies are usually combined with plate fixation to keep the spinal curvature, and increasing the rate of fusion (Song et al., 2014). The insertion of a plate over multiple vertebral bodies requires more tissue retraction which may increase the risk of occurrence of complications, as screw breakage, pull out, esophageal injury and recurrent laryngeal nerve injury (El-Tantawy, 2015).

Such complications, can compromise the satisfactory final outcome decompression of the spinal cord and/or nerve roots and bone fusion with maintenance of cervical lordotic curvature (Roguski et al., 2014).

The goal of this study was to evaluate the efficacy of anatomical polyetheretherketone (PEEK) cages in successive four levels anterior cervical discectomy without plating as a surgical option rather than anterior cervical corpectomy, fixation by plate or posterior cervical laminectomy, and assessment of post spinal surgery pain.

\section{PATIENTS AND METHODS}

This was a prospective study including twenty adult patients with symptomatic four levels cervical disc disease operated upon by anterior cervical discectomy with inter-body cage fusion in the Neurosurgery Department at Al Hussein 
University Hospital and Sednawy Health Insurance Hospital. The study was performed through the period from January 2018 to June 2020, and the follow up period was 24 months.

\section{Inclusion criteria:}

Symptomatic patients with successive four levels cervical disc disease presented with clinical signs of cervical radiculopathy and failed medical treatment, and patients with clinical signs of cervical myelopathy.

\section{Exclusion criteria:}

Patients with contraindication to general anesthesia, and patients who were subjected to previous cervical spine surgery.

All patients included in the study were subjected to a thorough history, general and neurological examination. Routine preoperative laboratory investigations were performed and radiological investigations included plain $\mathrm{x}$-rays cervical spine for all patients, including antero-posterior view, dynamic views to assess stability, oblique views for foraminal and facet details and the standard lateral view to assess curvature, sagittal rotation and alignment. Magnetic resonance imaging (MRI) of the cervical spine imaging was performed for all patients. Computerized tomography (CT) was done in selected patients.

\section{Surgical technique:}

A standard anterior Smith-Robinson approach was performed in all patients for microscopic anterior cervical discectomy with inter-body fusion.

\section{Outcomes and follow up:}

All patients were encouraged for ambulation as early as possible. Those patients with motor weakness were closely monitored for proper hydration, and prophylactic anticoagulation was started as early as possible in addition to the intensive rehabilitation programs.

All patients were subjected to a complete and detailed postoperative neurological evaluation including neurological state motor, sensory, reflexes, and complications pain through the visual analogue scale (VAS), spinal curves, mobility and fusion status with Xray were recorded and evaluated.

Radiological follow up was performed with regular post-operative anteroposterior (AP) and lateral views of the cervical spine. Flexion/extension Xray views were performed at the sixth week, 3rd month, 6th month, and one year postoperatively.

The cervical levels were defined to be successfully fused if there was no change in mobility of the fused levels on flexion and extension views obtained at $12-24$ months postoperative without pain and with intact hardware. Fusion was assessed by existence of trabecular continuity, bone mass bridging across the disc space and a cloudy interface between the cage and the end-plates.

An approval of the study was obtained from Al-Azhar University academic and ethical committee. Every patient signed an informed written consent for acceptance of participation in the study.

Statistical analysis was performed by SPSS (Statistical Package for the Social Sciences, IBM Corp. Released 2010. IBM 
SPSS Statistics for Windows, Version 19.0. Armonk, NY: IBM Corp.) Comparative tests were made between the base line VAS and the 24th month postoperative VAS.

Description of quantitative variables was presented in the form of mean \pm standard deviation (SD). Comparative tests were made between the pre-operative
VAS and the $24^{\text {th }}$ month post-operative VAS measurements.

The Wilcoxon Signed-Rank test was used to compare changes in the mean values after 24 months of the intervention with regard to quantitative variables.

$P$ value less than 0.05 was considered significant.

\section{RESULTS}

This study included 20 patients with symptomatic four levels cervical disc prolapse. All included patients had prolapsed C3-C4, C4-C5, C5-C6, and C6$\mathrm{C} 7$ levels (Figure 2); none of the included patients had a $\mathrm{C} 2-\mathrm{C} 3$ disease.

The study included 11 men and 9 women. The mean age at presentation was $56.1 \pm 14.26$ years. Five patients $(25 \%)$ had diabetes mellitus, three patients (15\%) had hypertension, and six patients $(30 \%)$ were active smokers at the time of surgery (Table 1).

All patients were subjected to anterior cervical discectomy with inter-body fusion with anatomical PEEK cages without plating. The mean follow up period was $25.05 \pm 2.46$ months.

Table (1): Distribution of the studied patients according to age $(n=20)$

\begin{tabular}{|c|c|c|c|}
\hline Age (years) & No. $(\%)$ & M & F \\
\hline $4^{\text {th }}$ decade & $2(10 \%)$ & $1(5 \%)$ & $1(5 \%)$ \\
\hline $5^{\text {th }}$ decade & $4(20 \%)$ & $3(15 \%)$ & $1(5 \%)$ \\
\hline $6^{\text {th }}$ decade & $9(45 \%)$ & $5(25 \%)$ & $4(20 \%)$ \\
\hline $7^{\text {th }}$ decade & $5(25 \%)$ & $2(10 \%)$ & $3(15 \%)$ \\
\hline Min. - Max. (age) & \multicolumn{3}{|c|}{$49-65$} \\
\hline Mean \pm SD. & \multicolumn{3}{|c|}{$56.1 \pm 14.26$} \\
\hline
\end{tabular}

No.: Number of patients, M: male, F: female, SD: standard deviation

The mean duration of symptoms before diagnosis was 14 months (range 24- 60 months). At the time of diagnosis, the most common symptoms presented were neck pain, brachialgia, heaviness of the lower limbs, and urinary incontinence (Table 2).

Table (2): Clinical presentation of the patients $(n=20)$

\begin{tabular}{|c|c|c|}
\hline Symptoms & No. & $\%$ \\
\hline Neck pain & 17 & $85 \%$ \\
\hline Brachialgia & 15 & $75 \%$ \\
\hline Lower limbs heaviness & 6 & $30 \%$ \\
\hline Incontinence & 3 & $15 \%$ \\
\hline
\end{tabular}

Summary of changes in symptoms was illustrated in (Table 3) 
Table (3): Post-Operative results regarding symptoms

\begin{tabular}{|c|c|c|c|}
\hline Symptoms & Improved & Worsen & No change \\
\hline Neck pain & $15(75 \%)$ & - & $2(10 \%)$ \\
\hline Brachialgia & $15(75 \%)$ & - & - \\
\hline Lower limbs heaviness & $5(25 \%)$ & - & $1(5 \%)$ \\
\hline Incontinence & $2(10 \%)$ & - & $1(5 \%)$ \\
\hline
\end{tabular}

The mean pre-operative VAS was $6.05 \pm 1.14$; follow up thorough the postoperative period showed declining of the score with statistically significant changes at the 24th months follow up P-value $<$ .001 (Figure 1 and Tables 4 and 5).

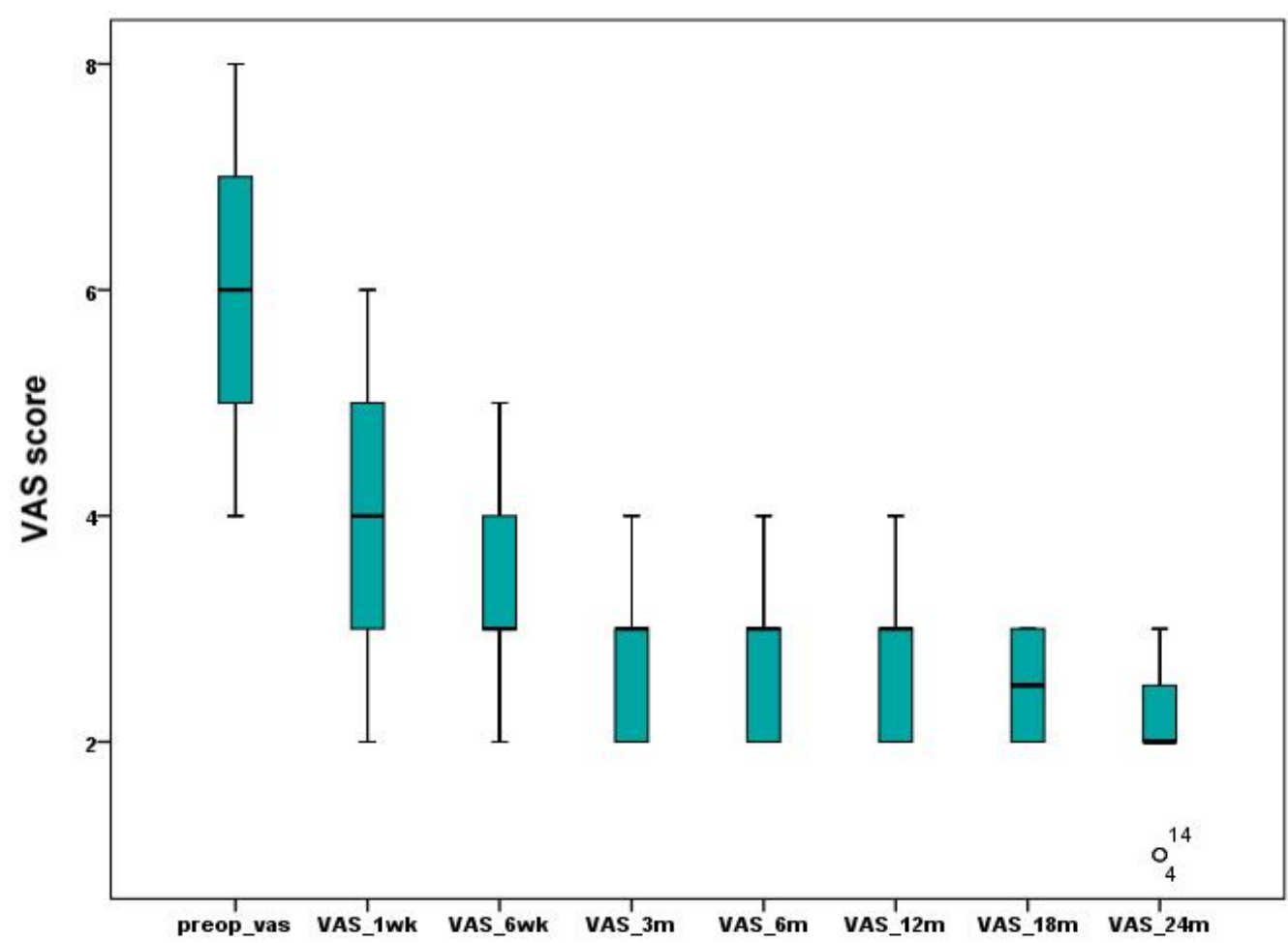

Figure (1): Plots and whiskers graph showing the changes in the mean VAS during the follow up period

Table (4): Description of the pre-operative and 24th months post operative VAS values

\begin{tabular}{|c|c|c|c|c|c|c|c|c|}
\hline \multicolumn{9}{|c|}{ Descriptive Statistics } \\
\hline Differences & \multirow{2}{*}{$\mathrm{N}$} & \multirow{2}{*}{ Mean } & \multirow{2}{*}{$\begin{array}{c}\text { Std. } \\
\text { Deviation }\end{array}$} & \multirow{2}{*}{ Minimum } & \multirow{2}{*}{ Maximum } & \multicolumn{3}{|c|}{ Percentiles } \\
\hline Values & & & & & & $25^{\text {th }}$ & $50^{\text {th }}$ (Median) & 75 th \\
\hline preop_vas & 20 & 6.0500 & 1.14593 & 4.00 & 8.00 & 5.0000 & 6.0000 & 7.0000 \\
\hline VAS_24m & 20 & 2.1500 & .58714 & 1.00 & 3.00 & 2.0000 & 2.0000 & 2.7500 \\
\hline
\end{tabular}


AHMED EL-SAYED AHMED et al.,

Table (5): The Wilcoxon Signed-Ranks test result summary

\begin{tabular}{|c|c|c|c|c|c|c|}
\hline \multicolumn{5}{|c|}{ Ranks } & \multicolumn{2}{|c|}{ Test Statistics ${ }^{b}$} \\
\hline & & $\mathrm{N}$ & $\begin{array}{l}\text { Mean } \\
\text { Rank }\end{array}$ & $\begin{array}{l}\text { Sum of } \\
\text { Ranks }\end{array}$ & & $\begin{array}{l}\text { VAS_24m - } \\
\text { preop_vas }\end{array}$ \\
\hline \multirow{4}{*}{$\begin{array}{l}\text { VAS_24m - } \\
\text { preop_vas }\end{array}$} & Negative Ranks & $20^{\mathrm{a}}$ & 10.50 & 210.00 & $\mathrm{Z}$ & $-3.946^{\mathrm{a}}$ \\
\hline & Positive Ranks & $0^{\mathrm{b}}$ & 0.00 & 0.00 & \multirow{3}{*}{$\begin{array}{l}\text { Asymp. Sig. (P- } \\
\text { value) (2-tailed) }\end{array}$} & \multirow{3}{*}{$<0.001$} \\
\hline & Ties & $0^{\mathrm{c}}$ & & & & \\
\hline & Total & 20 & & & & \\
\hline & \multicolumn{4}{|c|}{$\begin{array}{l}\text { a. VAS_24m }<\text { preop_vas } \\
\text { b. VAS_24m }>\text { preop_vas } \\
\text { c. VAS_24m }=\text { preop_vas }\end{array}$} & \multicolumn{2}{|c|}{$\begin{array}{l}\text { a. Based on positive ranks. } \\
\text { b. Wilcoxon Signed Ranks Test }\end{array}$} \\
\hline
\end{tabular}

Regarding complications: Only one patient had a transient hoarseness of voice which was treated conservatively by

\section{DISCUSSION}

Anterior cervical discectomy and fusion is a widely used procedure to treat multiple of cervical spinal pathologies, as cervical spondylotic myelopathy, degenerative disc prolapse and trauma. Regarding single-level ACDF the studies concluded that it can achieve a variable fusion rate from $92 \%$ to $100 \%$ and a relief of neurological symptoms, which varied from $70 \%$ to $90 \%$. Multilevel ACDF still faces a difficulty, as autogeneous bone fail to keep the spinal stability in multilevel discectomies properly and the complications rate related to the autogenous bone graft increases when to compared to single level, such as graft collapse $20-30 \%$ seen in multilevel cases (Kim et al., 2018).

In this study, the mean duration of symptoms before diagnosis was 14 months (range 24-60 months). At the time of diagnosis, the most common symptoms presented were neck pain $(85 \%)$, Brachialgia (75\%), heaviness of the lower limbs (30\%), and urinary incontinence $(15 \%)$. steroids, speech therapy and reassurance and it completely recovered by the sixth week post operatively.

Alaghory et al. (2018) mentioned that the median duration of symptoms before the initial diagnosis was twenty-four months (range 6-24 months). There were 16 patient presented by myelopathy and radiculopathy and 12 patient with only myelopathy.

In this study, all patients were managed by anterior cervical discectomy and fusion by stand-alone PEEK cages for four levels. Visual Analogue Score (VAS) was followed up during different postoperative periods. It was improving by time reaching $2.15 \pm 0.58$ by the 24 th month postoperative.

Alaghory et al. (2018) performed four levels anterior cervical discectomy and fusion using peek cages only. With perioperative assessment and scoring clinically and radio logically (Japanese Orthopedic Association [JOA] scores, Visual Analogue Scale [VAS] scores for assessment of neck and arm pain. The mean JOA score and VAS showed improvement by the third month postoperative. 
Pereira et al. (2013) mentioned that they had significant improvements for both neck and arm VAS scores, and had significant improvements from pre-to postoperative myelopathy scores.

Wang et al. (2018) demonstrated improvements in JOA and NDI scores after surgery with no significant differences between groups. There were no significant differences at follow up time point.

Gerszten et al. (2016) found that zeroprofile instrumentation and PEEK cages to be both safe and effective for patients who underwent three- and four-level ACDF, comparable to reports using plates. The rates of dysphagia for the entire cohort were indeed lower than in previously reported series using plate fixation devices for three- and four-level ACDF. PEEK cages alone compared to zero-profile devices were found to have a slightly higher incidence of both symptomatic subsidence as well as adjacent level degeneration. Zero-profile segmental fixation devices and PEEK cages may be considered over plates for patients requiring multi-level anterior cervical fusion surgery.

In this study, one patient (5\%) had a complication; which was a transient hoarseness of voice, which was treated by steroids, speech therapy, and reassurance, and it completely recovered by the sixth week post operatively. Alaghory et al. (2018) mentioned that post-operative complications occurred in the form of Hoarseness of voice post-operatively, and recovery has been achieved within one month.

Wang et al. (2018) mentioned that there were no instances of perioperative cerebral fluid leakage, hematoma, cage migration, or hardware-related complications in either group. Patients with pseud arthrosis or cage subsidence were asymptomatic. Patients were treated conservatively using oral neurotrophic drugs, hyperbaric oxygen therapy, and exercise. All symptoms had resolved by the third postoperative month. No patients required reoperation.

\section{CONCLUSION}

The procedure of multi-level anterior cervical discectomy with PEEK interbody cage fusion without plate fixation at four levels appeared safe and efficient to improve symptoms of pain and myelopathy, short inpatient hospital stay and potentially short procedure duration. Clinical outcomes compared favorably to other similar series and importantly, complications associated with anterior plate fixation were avoided.

Conflict of interest: The authors declare no conflict of interest.

Funding sources: The authors have no funding to report.

Acknowledgement: The authors are grateful for the patients without whom this study would not have been done.

\section{REFERENCES}

1. Alaghory I, Soliman HAG and Abdelhameed SM. (2018): Four Levels Anterior Cervical Discectomy and Fusion by Stand Alone PEEK Cages. Open Journal of Modern Neurosurgery, 08, 162-173.

2. Cho DY, Lee WY, and Sheu PC. (2014): Treatment of multilevel cervical fusion with cages. Surg Neurol., 62:378-385.

3. Cramer GD. (2013): General characteristics of the spine. In Cramer GD and Darby SA (eds) Clinical anatomy of the spine, spinal cord, and 


\section{AHMED EL-SAYED AHMED et al.,}

ANS.Pbl ${ }^{\odot}$ Elsevier Health Sciences, Phial, Pa: 15-64.

4. De la Garza-Ramos, R., $\mathrm{Xu}, \mathrm{R}$., Ramhmdani, S., Kosztowski, T., Bydon, M., Sciubba, D. M., Wolinsky, J., Witham, T. F., Gokaslan, Z. L., and Bydon, A. (2016): Long-term clinical outcomes following 3- and 4-level anterior cervical discectomy and fusion, Journal of Neurosurgery: Spine SPI, 24(6): 885-891.

5. Elias A, Kyriaki P, Polychronios S, Ioannis B, Athanasios S, and Ioannis P. (2017): Stand-Alone Anterior Cervical Decompression and Fusion in Three Levels with Peek Cages: A Possible Satisfactory Alternative. J. Neurol. Neurosci., 08 (06):e237:1-4.

6. El-Tantawy A. (2015): Is it possible to eliminate the plate-related problems and still achieve satisfactory outcome after multilevel anterior cervical discectomy?, Eur. J. Orthop. Surg. Traumatol., 25, (S1):135-145.

7. Gerszten PC, Pasche E, Mashaly H, Sabry H, Jalalod'din H, and Saoud K. (2016): Outcomes Evaluation of Zero-Profile Devices Compared to Stand-Alone PEEK Cages for the Treatment of Three- and Four-Level Cervical Disc Disease. Cureus., 8(9):e775:1-17.

8. Izzo R., Guarnieri G, Guglielmi G, and Muto M. (2013): Biomechanics of the spine. Part II: Spinal instability. European Journal of Radiology, 82(1): 127-138.

9. Kim YS, Park JY, Moon BJ, Kim SD, and Lee JK. (2018): Is standalone PEEK cage the gold standard in multilevel anterior cervical discectomy and fusion (ACDF)? Results of a minimum 1-year follow up, J. Clin. Neurosci., 47: 341-346.
10. Pereira EA, Chari A, Hempenstall J, Leach JC, Chandran H, and Cadoux-Hudson TA. (2013): Anterior cervical discectomy plus intervertebral polyetheretherketone cage fusion over three and four levels without plating is safe and effective long-term. J Clin Neurosci., 20(9):1250-1255.

11. Roguski M, Benzel EC, Curran JN, Magge SN, Bisson EF, Krishnaney AA, Steinmetz MP, Butler WE, Heary RF, and Ghogawala Z. (2014): Postoperative Cervical Sagittal Imbalance Negatively Affects Outcomes After Surgery for Cervical Spondylotic Myelopathy, Spine (Phila. Pa. 1976). 39(25): 2070-2077.

12. SaterenZoller E, Cannella D, Chyatte D, Fogelson J, and Sharma M. (2015): Diagnosis and medical and surgical management of cervical spondylotic myelopathy. Journal of the American Academy of Pas, 28(10): 29-36.

13. Shousha M, Ezzati A, and Boehm H. (2012): Four-level anterior cervical discectomies and cage-augmented fusion with and without fixation. Eur Spine J., 21:2512-2519.

14. Song KS, Piyaskulkaew C, Chuntarapas T, Buchowski JM, Kim HJ, Park MS, Kang H, and Riew KD. (2014): Dynamic Radiographic Criteria for Detecting Pseudarthrosis Following Anterior Cervical Arthrodesis, J. Bone Jt. Surgery-American, 96(7): 557-563.

15. Wang B, Lü G and Kuang L. (2018): Anterior cervical discectomy and fusion with stand-alone anchored cages versus posterior laminectomy and fusion for four-level cervical spondylotic myelopathy: a retrospective study with 2-year follow-up. BMC Musculoskelet Disord., 19(1):216-222. 


\section{تقييم نتائج إستثصال أربعة مستوبات من الغضاريف العنقية من الأمام في أمر اض الضه الفقر ات العنقية}

أحمد السيد أحمد، مأمون أبو شوشة، إسلام محمد الأجهوري، وائل عبد الفتاح حماد،

$$
\text { محمد برانيه، حسين منتصر رشدي }
$$

قسم جراحة المخ والأعصاب والأثعة التشخيصية، كلية الطب، جامعة الأزهر

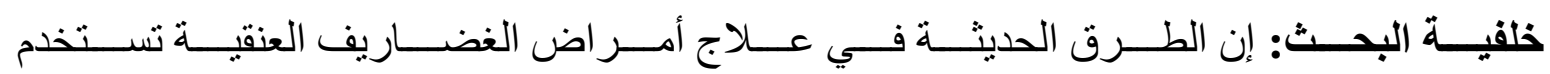

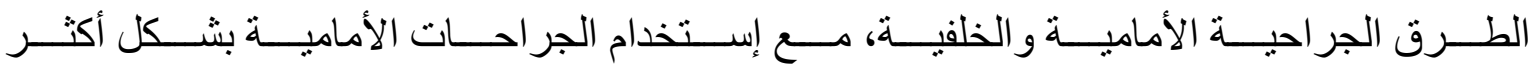

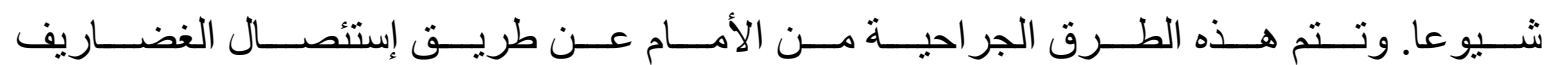

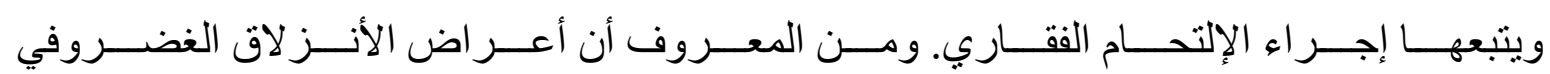

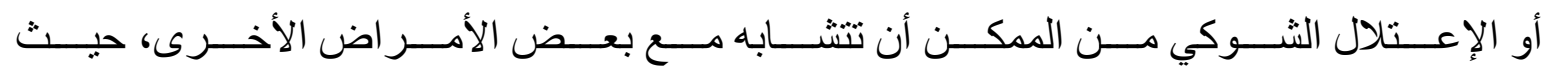

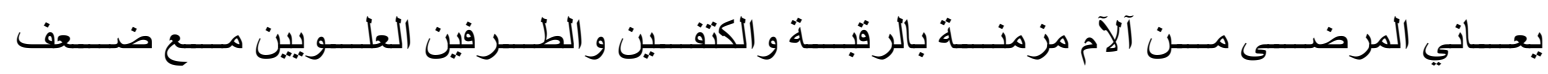

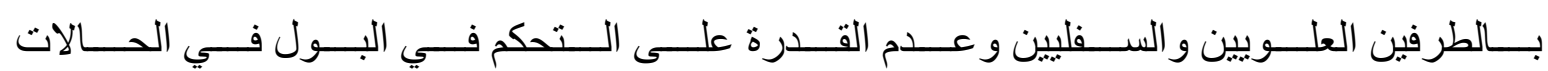
المتأخرة.

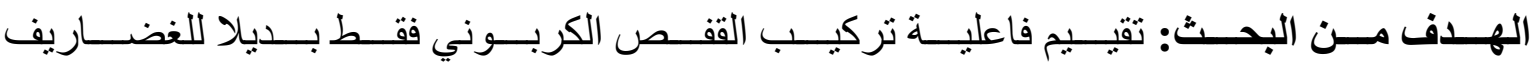

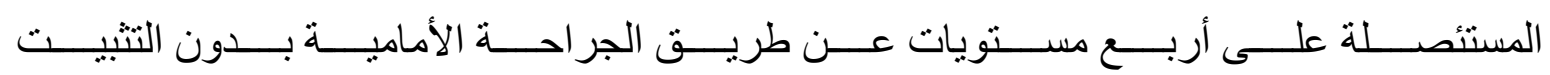

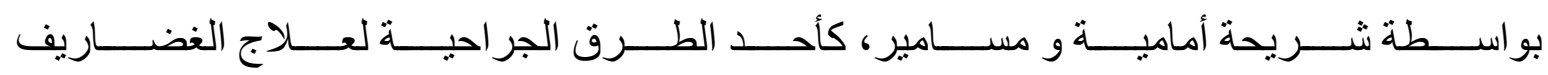

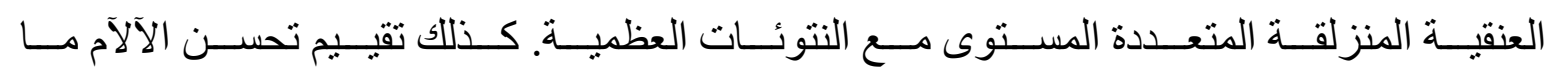
بعد الجر احة للفقرات العنقية.

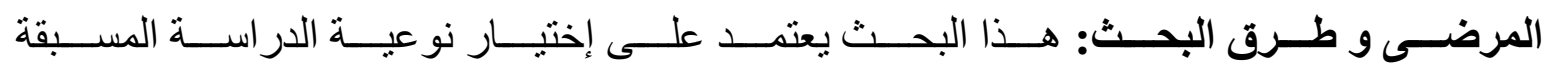

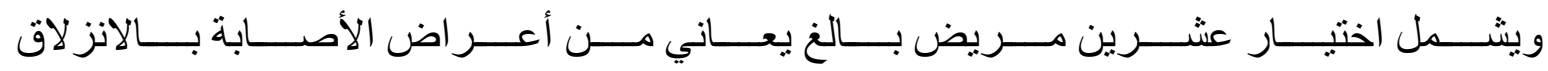

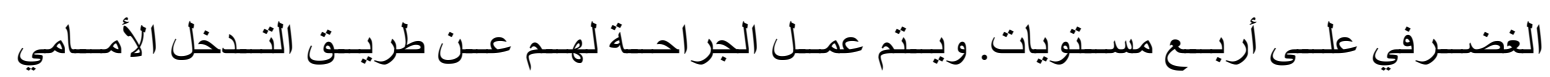

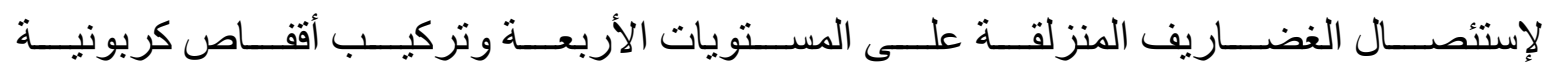

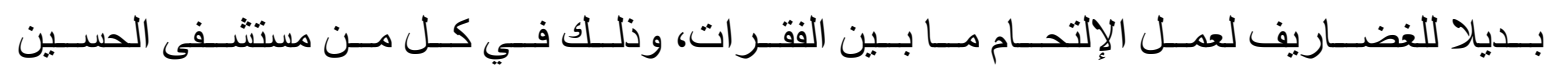

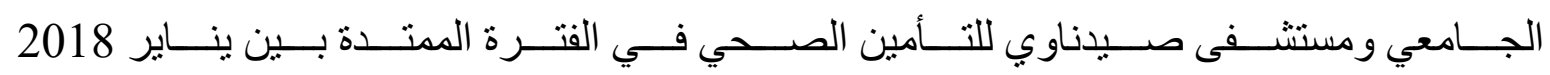




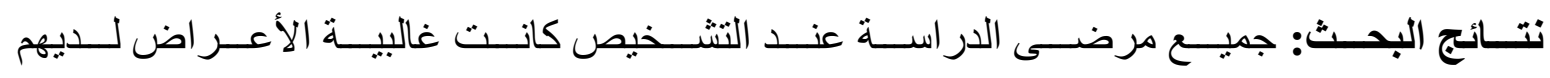

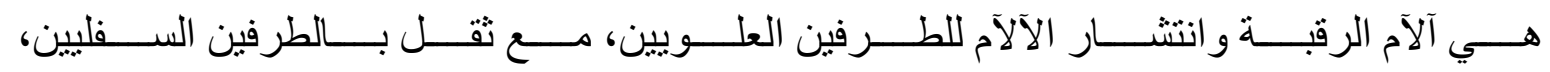

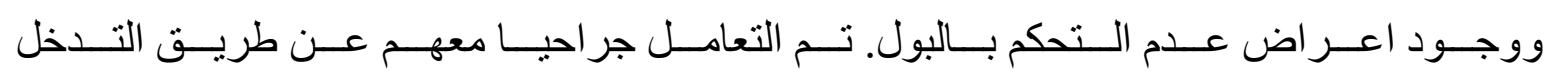

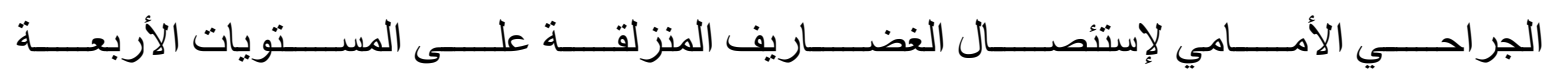

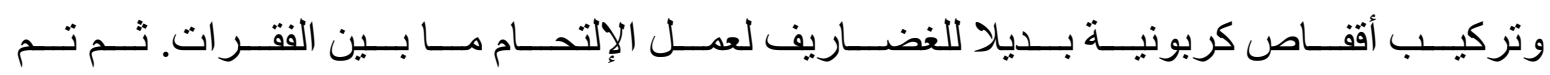

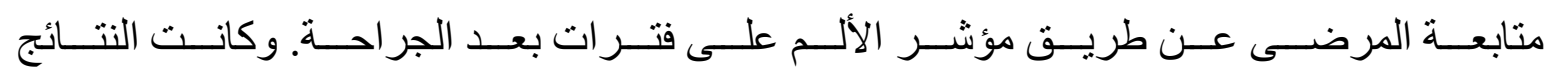
أن هناك تحسن ملحوظ في درجة الألم حتى بعد مرور سنتين من الجر احة.

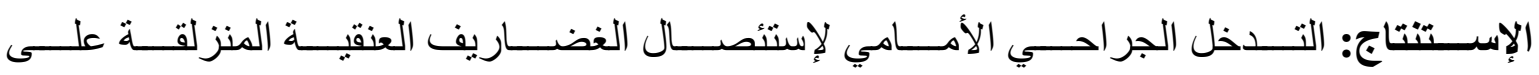

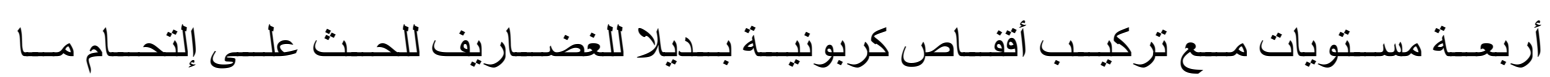

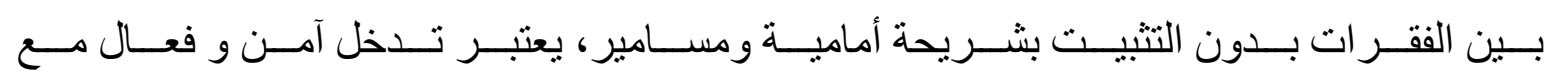

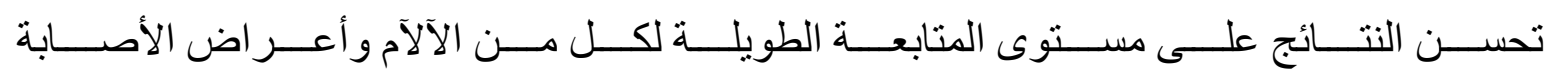

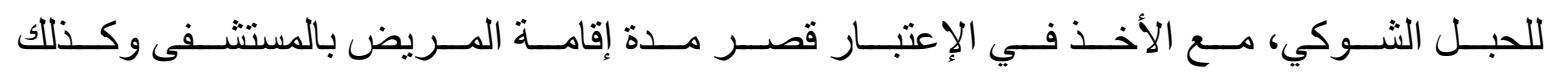
قصر مدة الجر احة نسبيا. 